\title{
Outbreak
}

\section{Yemen: Cholera outbreak and the ongoing armed conflict}

\author{
Fekri Dureab ${ }^{1}$, Khalid Shibib², Reema Al-Yousufi ${ }^{3}$, Albrecht Jahn \\ ${ }^{1}$ Public Health Institute, Heidelberg University, Heidelberg, Germany \\ 2 International Health Consultant, Henef, Germany \\ ${ }^{3}$ Ministry of Public Health and Population, Sana'a, Yemen
}

\begin{abstract}
Yemen was affected by a major cholera epidemic in 2016, while a civil war, which has devastated the country since March 2015 , has exacerbated the humanitarian situation. Cholera is a disease caused by the bacterium Vibrio cholera, thus this study aims to analyze the epidemiological features of the outbreak and explore the relation of the outbreak to the current armed conflict situation.

The data were obtained from the national surveillance system in Yemen. This contains details of 15,074 cases registered as suspected cholera patients per governorate from week 39 to 52 in 2016. In addition to the data concerning cholera, other data on conflict-related injuries, and population movement (numbers of Internally Displaced Persons - IDPs - and number of displaced returnees) were used to assess the correlation using Spearman's rho analysis.

The data analysis shows the intensity of the conflict as measured by the total casualties per governorate (conflict-related injuries and death) is significantly correlated with the number of cholera cases per governorate ( $\mathrm{r} 0.483, \mathrm{P}=0.026)$. The analysis also shows a positive, but not significant correlation between cholera cases, and both the number of conflict internal displaced people (IDPs) (r 0.389, $\mathrm{P}=0.081$ ), and number of returnees $(\mathrm{r}=432, \mathrm{P}=0.050)$.
\end{abstract}

Key words: cholera; conflict; Yemen.

J Infect Dev Ctries 2018; 12(5):397-403. doi:10.3855/jidc.10129

(Received 02 January 2018 - Accepted 10 April 2018)

Copyright $@ 2018$ Dureab et al. This is an open-access article distributed under the Creative Commons Attribution License, which permits unrestricted use, distribution, and reproduction in any medium, provided the original work is properly cited.

\section{Introduction}

Cholera is one of the crucial indicators of poor infrastructure and it is a continual risk to public health in the least developed countries worldwide [1]. Caused by the bacterium Vibrio cholera, cholera is an acute watery diarrheal disease [2]. The route of transmission is fecal-oral by contaminated water or food [3]. The World Health Organization has a standard case definition of cholera that can be adapted nationally and used by heath authorities to identify suspected cases [4]. A case of cholera is confirmed in a laboratory when vibrio cholera $\mathrm{O} 1$ or $\mathrm{O} 139$ is detected in any patient's diarrhea or vomitus [5].

Cholera seems obviously sensitive to conflict. Poverty, overcrowding, poor hygiene, contaminated food, and lack of safe drinking water are the main risk factors for cholera that may be a consequence of conflict. Alternatively, an existing cholera outbreak may be exacerbated by war and civil fighting. So far, knowledge of the relationship between cholera and conflict is limited or unknown, particularly in case of Yemen. This may be because cholera has an epidemic pattern, and affects a massive number of people across several areas of conflict. This is turn makes it difficult to manage outbreaks, due in particular to the lack of information [6].

Yemen is located in the south west of Asia, in the Arabian Peninsula. It is bordered by Saudi Arabia in the North and Oman in the East. The southern and western borders are bounded by Arabic sea and the Red Sea. The country's area is approximately 527,970 square kilometers. Yemen has a diverse topography; mountainous areas in the North, deserts and coastal landscape in the South and West. The country is divided into 23 governorates and 333 districts. The population of Yemen according to the most recent population projections is around twenty-six million [7,8]. Yemen is the poorest country in the Arabian Peninsula and among the poorest worldwide with low GDP (774.50 US dollars per capita) [9], low literacy rates, poor governance, high prevalence of poverty, critical food insecurity and widespread malnutrition. Since March 2015, a widespread armed conflict erupted in Yemen which exacerbated the humanitarian situation that has prevailed for over a decade. More than two years into the conflict, the situation has been further aggravated by fighting, population displacement, a lack of basic commodities and services, and a general deterioration 
of the economy. The occurrence of epidemics, especially cholera, is an obvious sign of basic services disruption [10].

The conflict has left 18.8 million people in need of assistance or protection including 10.3 million who are in acute need. An estimated 14.8 million people have no or limited access to basic healthcare, with chronic shortages in medical supplies; over 50 percent of health facilities are not functioning. In terms of access to safe drinking water and sanitation, around 14.4 million people require some form of assistance [11].

The public health facilities have been weakened by the escalating security and financial crisis of the Ministry of Public Health and Population (MOPHP). Apart from the irregularly-paid salaries of its 74,224 employees [12], no operational budget is provided by the Ministry of Finance. The lack of operational budget has resulted in further disruption of many healthcare services and poses a major threat to Yemen's public health. At the same time, the citizens are suffering from deepening poverty, food insecurity and inability to pay for essential services, especially in rural areas.

Despite some major pre-conflict achievements in the health system, it remains severely fragile. Yemen has some of the worst health indicators in the region, with maternal mortality at 148 per 100,000 and underfive mortality of 53 per 1,000 live births [13]. Health system indicators were also among the worst. Preconflict, there were around 4,207 public health facilities, including around 243 hospitals [14], which were severely understaffed and maldistributed in favour of urban areas. The rural population (around $79 \%$ of the country population, had to travel long distances to the nearest facility. As an example, the majority of maternal deaths either happened at home or on the way to the health facilities [15]. The current conflict has not just added to the socioeconomic decline and to the increased burden of population morbidity and mortality, but also resulted in a devastating blow to its national health service delivery system, involving its governance, financing, medical supply pipelines, human resources and health care delivery network.

The 2016 Health Resources Availability Mapping System (HeRAMS) survey carried out by WHO in 16 priority governorates covering 3,507 facilities showed that only $45 \%$ of health facilities are fully functional. Not a single doctor was available in 45 of the 267 districts surveyed. Out of 258 surveyed hospitals, only $37 \%$ were fully functional. The communicable diseases services were available only in $43 \%$ of the functional health facilities, the services of non-communicable diseases and mental health were the least available
( $21 \%$ of the facilities), and maternal and new-born services were available only in $35 \%$ of the facilities. The reduced access to these essential services causes excessive mortality among the population, particularly among mothers and children, and especially in rural areas [16].

Yemen has undergone several outbreaks of cholera during the last ten years; the last outbreak was in 2011 with the beginning of youth demonstration against the regime. At that time, more than thirty thousand patients were registered as cholera patients, with 134 fatal cases. The case fatality rate was $0.42 \%$ which was much less than the case fatality rates during the outbreaks of 2009 and 2010 (respectively $5.45 \%$ and 1.33\%) [17-19].

This cholera outbreak occurred during the ongoing armed conflict in Yemen in 2016, thus this study aims to analyze the epidemiological characteristics of the outbreak and the correlation between the current outbreak and ongoing armed conflict.

\section{Methodology}

This study used a quantitative method for data analysis to describe the severity of the outbreak and its epidemiological characteristics. This study used all the registered cases as suspected cholera patients $(15,074)$ from week 39 to week 52 of the year 2016. These were diagnosed clinically according to the Ministry of Health -WHO case definition, and a total of 216 stool samples from 17 governorates have tested positive for Vibrio Cholera, serotype O1.

A cholera line list was obtained from the national surveillance system in Yemen. These data were reported by the health facilities in different districts and governorates and collected centrally by the Cholera Task Force Committee at the Ministry of Health. There are many risk factors associated with a cholera outbreak; in this study, we focused on the conflictrelated factors, as seen in the framework in Figure 1.

Figure 1. The framework of factors associated with a cholera outbreak.

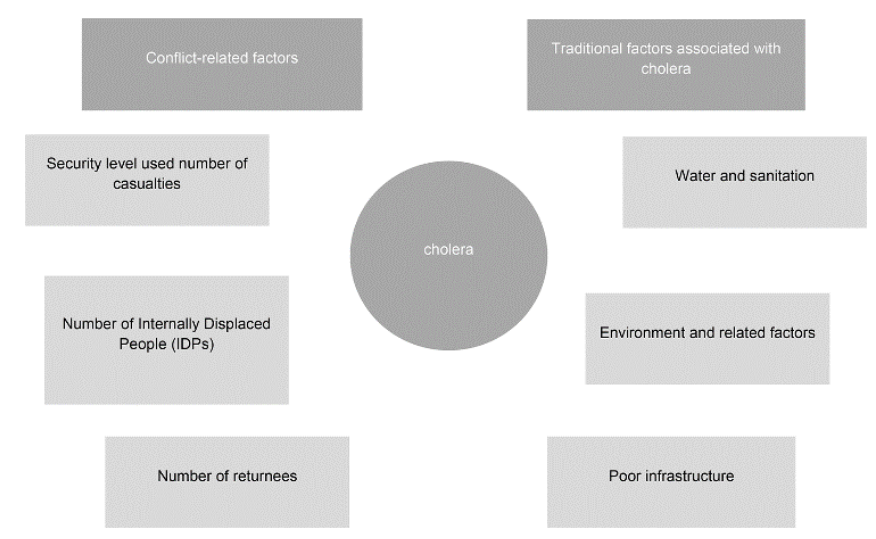


To determine whether the cholera outbreak correlates with the current conflict in Yemen, some conflict-related indicators by districts were analysed using Spearman's rho analysis (SPSS 20)

\section{Conflict-related factors}

1 - According to the data concerning casualties as obtained from the operational room of the emergency department in the Ministry of Health and published monthly by WHO, from 19 March 2015 to 31 December 2016, a total of 7,469 deaths and 40,483 injuries were reported across the country. However, the actual number of deaths is expected to be higher than the number of deaths reported by health facilities. In this study we used the casualty data from January to
Figure 2. Epidemiological trend of cholera outbreak from week 39 - week 52, 2016.

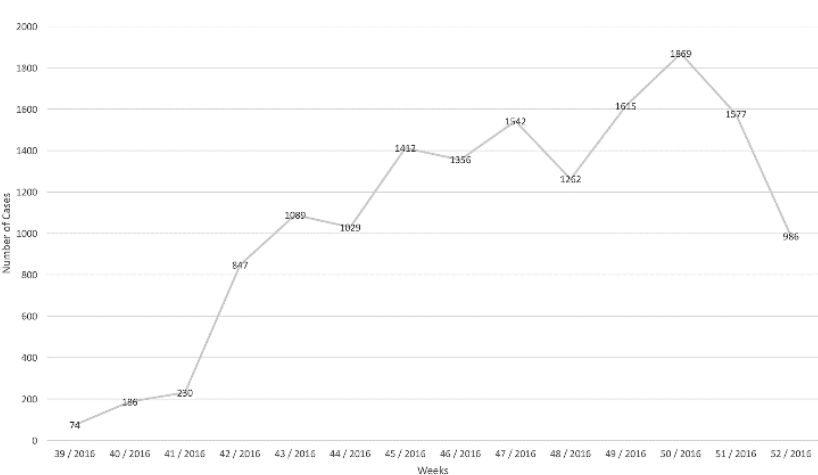

Table 1. Number of reported cases according to age and governorates.

\begin{tabular}{|c|c|c|c|c|c|}
\hline \multirow{2}{*}{ Governorates } & & \multicolumn{3}{|c|}{ Age groups in years } & \multirow{2}{*}{ Total } \\
\hline & & $>5$ & $6-17$ & 18 and above & \\
\hline \multirow{2}{*}{ Abyan } & Count & 9 & 12 & 25 & 46 \\
\hline & $\%$ & $19.6 \%$ & $26.1 \%$ & $54.3 \%$ & $0.3 \%$ \\
\hline \multirow{2}{*}{ Aden } & Count & 371 & 483 & 707 & 1561 \\
\hline & $\%$ & $23.8 \%$ & $30.9 \%$ & $45.3 \%$ & $10.4 \%$ \\
\hline \multirow{2}{*}{ Al-Baidha } & Count & 676 & 435 & 379 & 1490 \\
\hline & $\%$ & $45.4 \%$ & $29.2 \%$ & $25.4 \%$ & $9.9 \%$ \\
\hline \multirow{2}{*}{ Al-Dhale'e } & Count & 658 & 306 & 294 & 1258 \\
\hline & $\%$ & $52.3 \%$ & $24.3 \%$ & $23.4 \%$ & $8.3 \%$ \\
\hline \multirow{2}{*}{ Al-Jawf } & Count & 27 & 4 & 9 & 40 \\
\hline & $\%$ & $67.5 \%$ & $10.0 \%$ & $22.5 \%$ & $0.3 \%$ \\
\hline \multirow{2}{*}{ Al-Mahweet } & Count & 9 & 0 & 3 & 12 \\
\hline & $\%$ & $75.0 \%$ & $0.0 \%$ & $25.0 \%$ & $0.1 \%$ \\
\hline \multirow{2}{*}{ Al-Hodeida } & Count & 1284 & 980 & 1060 & 3324 \\
\hline & $\%$ & $38.6 \%$ & $29.5 \%$ & $31.9 \%$ & $22.1 \%$ \\
\hline \multirow{2}{*}{ City of Sana'a } & Count & 128 & 64 & 52 & 244 \\
\hline & $\%$ & $52.5 \%$ & $26.2 \%$ & $21.3 \%$ & $1.6 \%$ \\
\hline \multirow{2}{*}{ Amran } & Count & 6 & 7 & 18 & 31 \\
\hline & $\%$ & $19.4 \%$ & $22.6 \%$ & $58.1 \%$ & $0.2 \%$ \\
\hline \multirow{2}{*}{ Dhamar } & Count & 7 & 5 & 5 & 17 \\
\hline & $\%$ & $41.2 \%$ & $29.4 \%$ & $29.4 \%$ & $0.1 \%$ \\
\hline \multirow{2}{*}{ Hajjah } & Count & 519 & 310 & 252 & 1081 \\
\hline & $\%$ & $48.0 \%$ & $28.7 \%$ & $23.3 \%$ & $7.2 \%$ \\
\hline \multirow{2}{*}{$\mathrm{Ibb}$} & Count & 629 & 342 & 494 & 1465 \\
\hline & $\%$ & $42.9 \%$ & $23.3 \%$ & $33.7 \%$ & $9.7 \%$ \\
\hline \multirow{2}{*}{ Lahj } & Count & 274 & 226 & 257 & 757 \\
\hline & $\%$ & $36.2 \%$ & $29.9 \%$ & $33.9 \%$ & $5 \%$ \\
\hline \multirow{2}{*}{ Rayma } & Count & 134 & 237 & 204 & 575 \\
\hline & $\%$ & $23.3 \%$ & $41.2 \%$ & $35.5 \%$ & $3.8 \%$ \\
\hline \multirow{2}{*}{ Sana'a Governorate } & Count & 422 & 278 & 294 & 994 \\
\hline & $\%$ & $42.5 \%$ & $28.0 \%$ & $29.6 \%$ & $6.6 \%$ \\
\hline \multirow{2}{*}{ Shabwah } & Count & 78 & 7 & 0 & 85 \\
\hline & $\%$ & $91.8 \%$ & $8.2 \%$ & $0.0 \%$ & $0.6 \%$ \\
\hline \multirow{2}{*}{ Taiz } & Count & 673 & 559 & 862 & 2094 \\
\hline & $\%$ & $32.1 \%$ & $26.7 \%$ & $41.2 \%$ & $13.9 \%$ \\
\hline \multirow{2}{*}{ Total } & Count & 5904 & 4255 & 4915 & 15074 \\
\hline & $\%$ & $39.2 \%$ & $28.2 \%$ & $32.6 \%$ & $100.0 \%$ \\
\hline
\end{tabular}


Table 2. Distribution of cholera attack and fatality rates stratified by governorates.

\begin{tabular}{|c|c|c|c|c|c|}
\hline Governorates & $\begin{array}{c}\text { Estimated } \\
\text { population } 2016\end{array}$ & Cases & $\begin{array}{l}\text { Attack rate } \\
/ 100,000\end{array}$ & $\begin{array}{c}\text { Deaths } \\
(\%)\end{array}$ & Case fatality \\
\hline Abyan & 571,569 & 46 & 8.05 & $0(0 \%)$ & $0.0 \%$ \\
\hline Aden & 888,203 & 1561 & 175.75 & $16(21 \%)$ & $1.0 \%$ \\
\hline Al-Baidha & 749,575 & 1490 & 198.78 & $6(8 \%)$ & $0.4 \%$ \\
\hline Al-Dhale'e & 713,778 & 1258 & 176.25 & $1(1 \%)$ & $0.1 \%$ \\
\hline Al-Hodeida & $3,065,921$ & 3324 & 108.42 & $13(17 \%)$ & $0.4 \%$ \\
\hline Al-Jawf & 542,582 & 40 & 7.37 & $0(0 \%)$ & $0.0 \%$ \\
\hline Al-Mahweet & 789,145 & 12 & 1.52 & $4(5 \%)$ & $33.3 \%$ \\
\hline (capital city) Sana'a & $2,890,950$ & 244 & 8.44 & $0(0 \%)$ & $0.0 \%$ \\
\hline Amran & $1,100,880$ & 31 & 2.82 & $1(1 \%)$ & $3.2 \%$ \\
\hline Dhamar & $1,939,352$ & 17 & 0.88 & $1(1 \%)$ & $5.9 \%$ \\
\hline Hajjah & $2,099,064$ & 1081 & 51.50 & $2(3 \%)$ & $0.2 \%$ \\
\hline $\mathrm{Ibb}$ & $2,884,823$ & 1465 & 50.78 & $12(16 \%)$ & $0.8 \%$ \\
\hline Lahj & 994,516 & 757 & 76.12 & $0(0 \%)$ & $0.0 \%$ \\
\hline Rayma & 581,021 & 575 & 98.96 & $2(3 \%)$ & $0.3 \%$ \\
\hline Sana'a & $1,086,942$ & 994 & 91.45 & $7(9 \%)$ & $0.7 \%$ \\
\hline Shabwah & 629,569 & 85 & 13.50 & $2(3 \%)$ & $2.4 \%$ \\
\hline Taiz & $2,764,727$ & 2094 & 75.74 & $9(12 \%)$ & $0.4 \%$ \\
\hline Total & $24,292,617$ & 15074 & 62.05 & $76(100 \%)$ & $0.5 \%$ \\
\hline
\end{tabular}

December 2016 and distribution of casualties by district to reflect the intensity of the conflict during the outbreak and in the period prior to the incidence of cholera [20].

2 - Number of internally displaced people and returnees collected from the 12 th report issued by the Task Force on Population Movement (TFPM), led by the Protection Cluster in Yemen. The number of displaced people has recently exceeded three million people, with 2,007,216 internally displaced persons (IDPs) and 1,027,674 returnees. They are in desperate need of humanitarian support, including health services. They are particularly susceptible to communicable diseases, creating an additional burden on the already overwhelmed health system [21].

\section{Results}

On 6 October 2016, a cholera epidemic was announced by the health authority in Yemen. Until the end of 2016, the Ministry of Public Health and Population (MOPH\&P) recorded a total of 15,074 suspected cases of cholera in 172 districts of 17 governorates. Stool samples were collected from 824 suspected cholera cases around $5.5 \%$ of the total suspected cholera cases in 2016, twenty-six percent of the stool samples were positive of serotype $\mathrm{O} 1$ (Ogawa). The trend in Figure 2 shows the number of cases per week, with the first case reported in the capital city of Sana'a in week 39. Gradually, the number of cases increased in several governorates from week 39 onwards with some fluctuations. The curve showed four peaks: the first peak was observed in week $43(1,089$ cases/week, reported by 13 governorates), the second peak was seen in week 45 (1,412 cases/week, reported by 13 governorates) and the third peak was noted in week 47 (1,542 cases/week; reported by 14 governorates). The most prominent peak was observed in week 50 (1,869 cases/week; reported by 15 governorates). Then the trend shows a sharp decline in the number of cases, starting in weeks 51 and 52.

The data analysis of this epidemic showed that 39\% of the patients were children under five years old, $28.2 \%$ of cases were among patients aged between 6 and 17 years, and $32.6 \%$ of patients were 18 years old and above. The median age of cases was 9 years old (from 0.1 to 95 years). $53.6 \%$ of cases were male. The highest number of cholera patients was reported in AlHodeida, and $66 \%$ of cases were seen in five of the seventeen governorates (Al-Hodeida, Taiz, Aden, Al Baidha and Ibb) (Table 1).

Table 2 shows the overall attack rate (AR) in the 17 governorates was $62.1 / 100,000$ population. The attack rate ranged between (0.88/100000 in Dhamar and $198 / 100000$ in Al-Baidha). A total of 76 deaths were reported with an overall case fatality rate (CFR) of $0.5 \%$, where Al-Mahweet had the highest fatality rate of $33 \%$, although the attack rate was $1.52 / 100000$.

The total casualties, including the injured and dead people per governorate, was significantly correlated with the number of cholera cases per governorate $(r$ $0.483, \mathrm{P}=0.026)$. Both conflict IDPs and returnees showed a positive correlation with cholera cases, the $\mathrm{P}$ values ( $\mathrm{r} 0.389, \mathrm{P}=0.081)$ and $(\mathrm{r}=432, \mathrm{P}=0.050)$ respectively see Table 3. 
Table 3. The correlation between cholera cases and conflict-related indicators.

\begin{tabular}{ccccc}
\hline Variables & Spearman's rho & Total casualties & Conflict IDPS & Conflict returnees \\
\hline Cholera & Correlation coefficient & $.483^{*}$ & .389 & .432 \\
& Sig. (2-tailed) & .026 & .081 & .050 \\
\hline
\end{tabular}

IDPs: Internal Displaced Persons.

\section{Discussion}

This study describes the most recent outbreak of cholera in Yemen, from the first wave which started in the beginning of the last quarter of the year 2016, and continuing to the date of writing of this paper with the second wave. The first wave of the outbreak started in three governorates (including the capital city of Sana'a) and spread throughout the country to include seventeen of the twenty-two governorates. The epidemiological curve showed some fluctuations since the first week of the incidence of cholera outbreak; this is due to the spread of the outbreak from one governorate to the next, as occurred in many similar cholera outbreaks in Nigeria and Bangladesh [22,23].

The intensity and extended length of the current conflict has hindered the vast majority of the population in obtaining easy access to basic services - particularly the most vulnerable groups of children and women. We found in this study that children are the most severely affected group in this outbreak: 39\% of suspected cholera cases were among children under five years old. Another study by Dalhat and colleagues showed that children from $0-59$ months represented the most affected group during the first wave of cholera outbreak in Nigeria in 2010 [22], and another study from Somalia showed that $58 \%$ of cholera cases were among children under five years old [24].

The human-made disaster in Yemen has led to disruption of the health system and associated social services, such as water and sanitation. This in turn has increased the rate of transmission of infectious disease such as during the current cholera outbreak. Many studies showed a close link between cholera and other disaster-related factors such as unplanned overcrowding, internally displaced people, poor water and sanitation, poor nutritional status, poor personal hygiene, limited access to health care and low coverage of vaccination [25].

This study shows the association between cholera and the ongoing conflict as reflected in the correlation between the number of reported cholera cases and reported conflict-related injuries and death $(\mathrm{r} 0.483, \mathrm{P}=$ $0.026)$, as it similarly occurred in many settings, an example being the cholera outbreak which occurred previously in four governorates of Yemen after the political crises and the civil war against the armed group in Abyan 2011 [26]. It also occurred in Kenya following post-election violence in 2008 [27], and in Liberia after the civil war in 2003 [28].

About two-thirds of the suspected cholera cases were registered in five (Al Hodeida, Ibb, Taiz, Albaida and Aden) of the seventeen governorates affected by the outbreak. Al-Hodeida and Ibb have both received a huge number of internally displaced people (IDPs) over the last two years [21]. The other three governorates, Aden, Al-Baidha and especially Taiz, have experienced active civil war fighting which has severely affected the health and social infrastructures in addition to the population movements into and out of these governorates. An open question is the outbreak situation in some governorates, which seriously affected in this war, where not a single suspected case of cholera was reported since the outbreak in Oct 2016, despite continuously reporting about distraction, death and injuries due to the hostilities in the same period in time. This can be explained by departure of a significant number of population to neighboring governorates as IDPs. It can also be attributed to the underreporting of cases by the disrupted governorate health system and/or to high awareness of health partners and the population, together with heavy humanitarian investment in water and sanitation since the beginning of the conflict.

A relationship between cholera in Yemen and the Horn of Africa (HOA) cannot be ignored as the cholera outbreaks rage over the Horn of Africa and the Great Lakes regions, with more than 63,000 cases in 2016 alone. The HOA countries are not only receiving Yemeni refugees, but are also the source of a high number of irregular migrants arriving in Yemen. Despite the conflict in Yemen, 27,123 irregular migrants arrived in June and July 2016, constituting the highest records of arrival since 2006 according to UNHCR data [29].

\section{Recommendation}

Public awareness messages on personal hygiene, food and water safety and an increased readiness of the public health authorities for surveillance (including public health laboratories at central and regional levels) 
on the one side, and response systems on the other side are key interventions. Coordination and leadership arrangements should be in place. Case definitions, rapid testing kits, case management protocols, and stocks of medical supplies should be prepared. The establishment of a simple community surveillance system associated with awareness and prevention component will help in identifying the warning signs of morbidity and mortality, and reduce the rapid spread of the cholera particularly in the context of Yemen.

\section{Acknowledgements}

We would like to thank the Ministry of Health and Population for their support and for providing us with the data to publish this work. We would also like to express our gratitude to the health cluster, the national cholera taskforce committee and eDEWS program in Yemen for their efforts and continuous updates.

\section{References}

1. World Health Organization (2007) Cholera, weekly epidemiological record. World Health Organization 31: 269284.

2. World Health Organization (2010) First Steps for Managing an Outbreak of Acute Diarrhoea. in GlobalL Task Force on Cholera Control. World Health Organization.available: http://apps.who.int/iris/bitstream/handle/10665/70538/WHO CDS_CSR_NCS_2003.7_Rev.2_eng.pdf;jsessionid=B9784C 4EEA 6382 B $2 \mathrm{EEB} 795 \mathrm{DA} 0 \mathrm{EF} 9 \overline{\mathrm{B}} 058$ ? sequence $=1$. Accessed 26 June 2017

3. World Health Organization (2010) Acute Diarrhoeal Diseases in Complex Emergencies: Critical Steps. in Global Task Force on Cholera Control. World Health Organization: Geneva. Available:

http://apps.who.int/iris/bitstream/handle/10665/70539/WHO CDS_CPE_ZFK_2004.6_Rev.1_eng.pdf?sequence=1.

Accessed: 26 June 2017

4. World Health Organization (2017) Standard case definition. Prevention and control of cholera outbreaks: WHO policy and recommendations.

Available: http://www.who.int/cholera/technical/prevention/control/en/in dex1.html. Accessed: 05 July 2017

5. Centers for Disease Control and Prevention (1997) Case definitions for infectious conditions under public health surveillance. MMWR 46: 10.

6. Kelly Hope LA (2008) Conflict and emerging infectious diseases. Emerg Infect Dis 14: 1004-1005.

7. Central Statistical Organization (2014) Population Estimates: 2005-2014 Projections. Central Statistical Organization, Ministry of Planning - Yemen. Available: https://data.humdata.org/dataset/yemen-cso-2017-populationprojections-by-governorate-district-sex-age-disaggregated. Accessed: 17 May 2017.

8. Nations Online (2016) Population figures for all countries. Available:

http://www.nationsonline.org/oneworld/population-bycountry.htm. Accessed: 10 August 2017
9. Trading econmics (2015) Yemen GDP per capita. Available: https://tradingeconomics.com/yemen/gdp-per-capita Accessed: 10 August 2017

10. European Commission Humanitarian Aid (2017) Humanitarian Aid and Civil Protection Factsheet. European Commission: Yemen. Available: https://reliefweb.int/report/yemen/echo-factsheet-yemenapril-2017. Accessed: 26 May 2017

11. United Nations Office for the Coordination of Humanitarian Affairs (2017) Humanitarian Needs Overview. UNOCHA: Yemen. Available: https://reliefweb.int/report/yemen/yemen2017-humanitarian-needs-overview-enar. Accessed: 20 May 2017

12. Ministry of Public Health and Population (2014) Health Human Resources, Genral Department of Human Resources. Ministry of Public Health and Population: Yemen. Available: http://www.moh.gov.ye/english/index.html. Accessed: 21 May 2017

13. Ministry of Public Health and Population and Central Statistical Organization (2013) Yemen National Health and Demographic Survey. Ministry of Public Health and Population, and Central Statistical Organization (CSO): Yemen.Available:http://www.moh.gov.ye/arabic/docs/Arabic \%20Report\%20Final.pdf. Accessed: 21 May 2017

14. Ministry of Public Health and Population (2014) Annual Statistical Health Report. Ministry of Public Health and Population:

Yemen.Available: http://www.moh.gov.ye/arabic/docs/Report2014.pdf. Accessed: 21 May 2017

15. Lindsay A (2015) Yemen: Humanitarian crisis indicates rise in maternal mortality.

Available:http://mothersmonument.org/2015/03/02/yemenmaternal-mortality/ Accessed: 13 Jauary 2018

16. World Health Organization and Ministry of Public Health and Population (2016) Service Availability and Health Facilities Functionality in 16 Governorates (Health Services and Resources Availability Mapping System). World Health Organization, Yemen Country Office and Ministery of Public Health and Population. Available:http://www.moh.gov.ye/arabic/docs/Reports/HeRA MS\%2016\%20Govn\%20final\%20report.pdf. Accessed: 2 June 2017

17. World Health Organization (2010) Cholera in 2009. Weekly epidemiological record, World Health Organization 31: 293308.

18. World Health Organization (2011) Cholera in 2010. Weekly epidemiological record, World Health Organization 31: 325340.

19. World Health Organization (2012) Cholera in 2011. Weekly epidemiological record, World Health Organization 31-32: 289-304.

20. World Health Organization (2017) Snap Shot of Health Facilities based Reported Deaths and Injuries 19 March - 31 December 2016. World Health Organizarion, Yemen Country Office: Sana'a, Yemen. Avaiable: http://www.emro.who.int/yem/yemeninfocus/yemencasualities.html. Accessed: 17 May.2017

21. Protection Cluster Yemen (2017), Task force on population movement (TFPM); 12th report executive summary. IOM and UNHCR p. 18. Available: https://reliefweb.int/sites/reliefweb.int/files/resources/taskforce-on-population-movement-12th-report-january-2017.pdf. Accessed 20 May 2017. 
22. Dalhat M, Isa A, Nguku P, Nasir S, Urban K, Abdulaziz M, Dankoli R, Nsubuga P, Poggensee G (2014). "Descriptive characterization of the 2010 cholera outbreak in Nigeria." BMC Public Health 14: 1167.

23. Siddique A, Islam Q, Akram K, Mazumder Y, Mitra A, Eusof A (1989). "Cholera epidemic and natural disasters; where is the link." Trop Geogr Med 41: 377-382.

24. World Health Organization (2016) Cholera Situation in Somalia October 2016. Eastern Mediterranean Regional Office.Available: $\quad$ http://www.emro.who.int/pandemicepidemic-diseases/cholera/cholera-situation-in-somalia-31july-2016.html. Accessed: 01 August 2017.

25. IKouadio I, Aljunid S, Kamigaki T, Hammad K, Oshitani H (2012) Infectious diseases following natural disasters: prevention and control measures. Expert Rev Antiinfect Ther 10: $95-104$

26. Qasem M, Al-Abhar N, Jumaan A (2013) The hazard of conflict: cholera outbreak in Abyan Yemen 2011. In A. Alsaruri (Ed.) Proceedings book First National YFETP Conference Book (pp.77) presented at The First Arab World Public Health Conference. Dubai, UAE.

27. Shikanga O, Mutonga D, Abade M, Amwayi S, Ope M, Limo H, Mintz E, Quick R, Breiman R, Feikin D (2009) High mortality in a cholera outbreak in western Kenya after postelection violence in 2008. Am J Trop Med Hyg 81: 1085-1090.

28. Centers for Disease Control and Prevention (2003) Cholera epidemic after increased civil conflict- Monrovia, Liberia, June-September 2003. MMWR 52: 1093-1095.

29. United Nations Office for the Coordination of Humanitarian Affairs (2016) Regional outlook for the horn of Africa and Great Lakes Region: Recommendations for humanitarian action and resilience response - October to December 2016. UN Office for the Coordination of Humanitarian Affairs p. 38. Available: https://reliefweb.int/report/world/regional-outlookhorn-africa-and-great-lakes-region-recommendationshumanitarian-action. Accessed: 01 August 2017.

\section{Corresponding author}

Fekri Dureab, MD, MSc.IH

Public Health Institute, Heidelberg University

Bernheimer Str. 20, 69115, Heidelberg, Germany

Phone: +4917620084242

Fax: +49 (0)6 221565039

Email: fekri.dureab@uni-heidelberg.de

Conflict of interests: No conflict of interests is declared. 